\title{
Chefia e Produção
}

\section{ZELYR XAVIER}

$C_{\text {Hefe }}$ - é o responsável pelo resultado final das atividades de sua equipe de trabalho.

Partindo da análise da própria conceituação, verificamos, logo, tratar-se - êsse resultado final do trabalho da equipe - da sua produção.

\section{RESPONSABILIDADE DO CHEFE NA PRODUÇÃO}

É atribuição precipua do Chefe tudo que se relacione com a produção: sua qualidade, a quantidade em que é feita e, sobretudo, as formas de que deve e terá de lançar mão para estimular seus empregados no sentido de conseguir o melhor, com o menor gasto, ou seja - produtividade.

Ao Chefe é debitada ou creditada tôda produção de sua equipe, desde que possa êle contar com os elementos indispensáveis àquela:

- pessoal e material -

sem o que, não se poderá responsabilizá-lo pelo débito da mesma.

\section{OBJETIVOS NA PRODUÇÃO}

Tôda produção deve ser feita tendo em vista: a necessidade do consumidor - quando se tratar de comércio - e os interêsses do contribuinte - tratando-se do Serviço Público.

Além dêsses dois objetivos deve, também, a produção observar o ritmo a ser obedecido no sistema a que pertencer.

$\mathrm{Na}$ indústria, êsse ritmo é, rigorosamente, observado tendo em vista que as etapas são sucessivas e ininterruptas.

Nas Repartições Públicas, também se faz necessário tal observância, pois, não raro, ocorre ser um serviço ràpidamente despachado para ficar empilhado na Seção seguinte.

Tal forma de produzir prejudica o conjunto, assim, nenhum Chefe deve pensar na sua produção, isoladamente, mas, como parte de um sistema cujo mecanismo deverá conhecer.

Produzir muito nem sempre é bom indice se não fôr acompanhado de
baixo preço de custo. 
Também não basta que haja grande venda, com preços elevados - isto faz com que o produto comece a ser mal feito e a clientela mal servida.

$\mathrm{O}$ ideal é atingir o «rendimento ótimo» que consiste em: boa qualidade, quantidade suficiente e a bom preço de custo, proporcionando justo preço de venda.

Esse deve ser o objetivo de todo Chefe no sentido de que sua produção atenda, de fato, à sua finalidade social de bem servir.

\section{ELEMENTOS DA PRODUÇÃO}

\section{0 - Pessoal - sua importância na produção}

Sob o ponto-de-vista econômico, os elementos classicos da produção são:

a) Natureza - elemento passivo é a matéria-prima.

b) Capital - é o elemento que fornece os meios, os instrumentos.

c) Trabalho - é o elemento impulsionador dos outros dois. É realizado pelo elemento humano, que é o principal, na produção.

Se êste elemento falhar, de nada valem os outros dois.

Os autores preocupavam-se, sobretudo, com a máquina, mas, nos últimos vinte anos, a preocupação maior passou a ser com o elemento humano.

Isto começou porque, até à $1 .^{a}$ guerra mundial, a economia era o fim e o homem o meio de alcançá-la - foi a chamada «era do homem econômico», pois, a preocupação era do lucro, acima do bem-estar humano.

Após a $2 .{ }^{\mathrm{a}}$ guerra, o homem passou a ter sôbre si as atenções da sociedade, constituindo esta a "era do homem social», quando, então, o dinheiro passou a ser usado a serviço do bem-estar humano.

Compreenderam, finalmente, que o homem era, de fato, o mais significativo, que, sem êle, nada poderia ser feito e, conseqüentemente, o seu bemestar teria influência benéfica na obtenção de maior lucro na produção.

Um homem bem nutrido, lògicamente, produz mais que um subnutrido.

Modernamente, a preocupação não se limita, apenas, ao problema da fome, para resolver os problemas do homem. Avançou até chegar, também, à solução dos problemas psicológicos do ser humano.

Desta preocupação surgiram estudos vários sôbre o modo como equacionar e solucionar tudo que pudesse interferir na produção através do seu elemento mais representativo - o homem.

\section{1 - Material - como instrumento na produção}

Para que se produza é necessário material que deverá ser de acôrdo com o objetivo ou tipo de produção a ser lograda.

Assim, é o material, nas mãos do Chefe, um dos instrumentos, o meio pelo qual êle conseguirá seu objetivo, seu fim - a produção.

Com os modernos estudos de Psicologia a preocupação constante dos administradores passou a ser o pessoal, embora seja da integração dos dois elementos - pessoal e material - que resultará o produto final. 
Dêste modo, ambos devem ser encarados pelo Chefe com especial atenção a fim de que se possa tirar o máximo de rendimento pelo uso de métodos e principios científicos dos quais resultará, forçosamente, produtividade e economia.

Um dos grandes problemas a enfrentar um Chefe quanto ao material diz respeito ao fornecimento na quantidade e ocasião desejadas.

Entretanto, o ritmo da produção não obedece ao do fornecimento o que impõe seja o pedido feito com antecedência e guardado nos Almoxarifados.

Tal medida, porém, acarreta inconvenientes porque, contendo com os cortes geralmente sofridos pelos pedidos, as Repartições solicitam material em excesso.

Falta contrôle das partes fornecedoras e de critério justo nos cortes que, por vêzes, prejudicam o bom andamento de serviços que se vêem impossibilitados de prosseguir enquanto que em outras o dito material acha-se empilhado, sem uso!

Por isso, deve haver, sempre, contrôle do consumo real a fim de que os cortes sejam feitos, sòmente, no excesso solicitado.

\section{2 - Orçamento - também como instrumento da produção}

O Orçamento é para o Chefe um dos meios através dos quais êle realizará seu trabalho e atingirá seus objetivos.

Deve, por isso, conhecer o lugar ocupado por sua unidade de trabalho no corpo do Orçamento do ponto-de-vista da quantidade de dinheiro de que disporá bem como o tempo em que deverá utilizá-lo.

\section{ECONOMIA E PRODUTIVIDADE}

Ainda como decorrência da produção temos a economia de gastos outra das responsabilidades do Chefe - e que para ser observada, torna-se necessário, por parte da Chefia, do conhecimento dos elementos da produção: pessoal, material e orçamento.

Não basta produzir muito, é preciso intima relação entre a produção e os gastos (produtividade).

O Chefe precisa produzir o melhor, pelo mais baixo preço de custo, a fim de que o preço de venda seja, também, baixo. Só assim teremos uma produção econômica e elevado indice de produtividade.

Se a produção fôr grande, e o preço alto, embora não dê prejuizo, não atinge sua finalidade social nem é econômico.

Esta preocupação com o preço da produção é mais observada na emprêsa privada.

No Serviço Público só excepcionalmente isto é observado.

O normal é o desperdício em suas mais variadas formas.

Não há responsabilidade porque não há responsáveis.

Não há prestação de contas do gasto em função da produção. 
Entretanto, há reflexos dessa irresponsabilidade na pessoa do contri $\nsim$ buinte que pagará êsses desperdícios e ficará, também, privado de que êsses capitais fôssem empregados, de outras formas, em seu benefício.

\section{CONHECIMENTOS NECESSÁRIOS AO CHEFE $6.0-$ Gerais}

Pela responsabilidade direta que tem o Chefe na produção de sua equipe, deverá êle ser dotado de qualidades, além de certas condições indispensáveis do ponto de-vista cultural. Assim, não se pode admitir que um Chefe não possua boa cultura geral que lhe permitirá mais flexibilidade nas decisões e maior visão de conjunto.

Êsses conhecimentos devem ser exigidos de acôrdo com o nivel da Chefia, assim, os Chefes responsáveis pelo serviço de uma equipe puramente técnica não precisará conhecer assuntos de igual teor dos que serão exigidos a uma Chefia que, pela sua natureza, possuir até um corpo de «staff».

No $1 .^{\circ}$ caso, os conhecimentos técnicos deverão ser maiores, bastando alguns de Administração Geral, exigindo-se o contrário para o 2. ${ }^{\circ}$, isto é, amplos conhecimentos de Administração Geral e um mínimo de técnica, porque: "a medida que cresce a escala hierárquica, aumenta a capacidade administrativa e diminui a técnica», segundo HENRY FAYOL.

\section{1. - Técnicos}

Já sabemos que os conhecimentos, pelo Chefe, da técnica da produção vai depender do nivel da Chefia e será, sempre, tanto menor quanto mais elevado fôr o seu nível.

Assim, numa obra de engenharia, o Chefe de um grupo de pedreiros não precisará ser um alto conhecedor de ciências complexas, mas, sobretudo, entender do modo como deverá ser feito, melhor, o trabalho de pedreiro a que se propuser.

Ao contrário, aquêle que dirigirá como Chefe de tôpo, precisará ser, obrigatòriamente, Engenheiro a fim de que possa supervisionar a parte técnica do serviço, e tratar, também, dos problemas gerais da construção, isto é, pessoal, compra de material, contrôle de gastos etc.

Neste caso, técnico por excelência, deverá o Chefe ser, também, técnico, mas, embora ajude, não é exigido, em todos os casos de Chefia, que o supervisor seja um especialista na técnica da produção da emprêsa, é preciso, isto sim, que êle possua informações, as mais gerais, sôbre a mesma.

Como exemplo podemos citar o ex-Ministro Salgado Filho que, embora civil, foi, e com êxito, Ministro da Aeronáutica.

\section{2. - Administração Geral}

São os meios através dos quais a emprêsa realiza seus fins.

Assim, uma emprêsa, para conseguir seus objetivos - atividades específicas - lança mão das atividades-meios, de cujos conhecimentos a Chefia não pode prescindir.

São êles: pessoal, material, Orçamento etc. 


\section{$6,2.0-$ Pessoal}

Do ponto-de-vista do pessoal, deve a Chefia conhecer como administrá-lo, a fim de que, com o emprêgo de princípios e normas da referida técnica, consiga o objetivo final a que visa a gerência do elemento humano: a eficiência ou seja - o máximo, o melhor, no menor espaço de tempo possivel e a inteiro contentamento de tôdas as partes interessadas.

As atividades da Administração de Pessoal são:

1.a) Atrair e obter pessoal qualificado para a organização

2.a) Manter êsse pessoal na organização

3.a) Aperfeiçoar e especializar o pessoal

4.a) Criar e manter elevado o moral dos servidores

5.a) Criar prestígio para a organização.

A atração ou obtenção de pessoal qualificado dependerá de seleção adequada, precedida de recrutamento bem cuidado.

Para manter o pessoal na organização devem ser usados todos os meios, ainda que para isso seja necessário elevar os salários.

Aperfeiçoar e especializar - é o treinamento em cursos, dentro ou fora do serviço, cuja responsabilidade é, notadamente, do Chefe.

O moral elevado do grupo vai depender do tratamento dado pela Chefia aos seus subordinados: mesmos direitos e vantagens, promoções justas, enfim, quando, de fato, a Chefia sabe impor-se, não transgredindo normas que possam prejudicar o grupo, parcial ou totalmente.

Criar prestigio para a função pública é tido como responsabilidade fundamental da Administração de Pessoal.

Para isso, deve o Chefe pôr em execução os quatro princípios que asseguram e mantém tal prestígio e que representam a filosofia da Administração do Pessoal.

São êles:

Principio da imparcialidade - quando o serviço é feito imparcialmente, com hierarquia na entrada dos processos e o trabalho é feito de acôrdo com os regulamentos existentes.

Principio da neutralidade - sem pressão política, servir não a homens, mas a principios, normas e regulamentos.

Principio do anonimato - produzir em nome da Administração e não no de quem produz, sem propaganda pessoal, portanto.

Principio do mérito - quando as funções de pessoal (recrutamento, seleção, promoção, etc.) são executadas à vista do valor pessoal dos candidatos, face às exigências dos órgãos. É a base ética do comportamento moral da Administração.

Para lograr os objetivos da Administração de Pessoal realizam-se funções que, segundo Mosher, são 26.

Pela importância, podemos enumerar as seguintes: 
Promoção - visa a estimular o servidor no trabalho. Deve ser, sempre, tendo em vista o mérito de cada um.

Avaliação da eficiência - é o problema mais importante da Administração de Pessoal e envolve outras funções: enquadramento, estágio probatório e promoção vertical. É o julgamento direto do Chefe sôbre o servidor no sentido de verificar o que êle está dando e o que o cargo exige dêle.

No Serviço Público a aplicação de tal função seria de grande valor para o serviço mas desastrosa para o pessoal - poucos continuariam nos seus cargos!

Como função auxiliar da avaliação da eficiência aparece o treinamento que muito poderá fazer para que o funcionário alcance índice de produção desejado.

A Assistência e Previdência Social, em 1880, foi por Owen considerada um fator de produção, assim, quanto maior fôsse a assistência dada ao empregado, mais êle produziria.

- Consiste no auxílio imediato ou mediato ao servidor através de: férias, creches, auxilios financeiros, pecúlios etc.

No Brasil, o exemplo máximo de Assistência Social é o I.R.B. onde, nos cinco andares que o compõem, îês são destinados ao bem-estar dos funcionários. guerra.

Relações Humanas no trabalho - foi a grande descoberta do após

Mosher, Stahal, Kingsley - concluíram que a preocupação de ordem técnica cedeu lugar à solução dos problemas de relações humanas, considerando-se mais importante formar Chefes e depois o grupo do que, apenas, técnicas sem conhecimento da Psicologia de grupo.

Dêstes estudos chegaram à conclusão que a ação da Chefia sôbre a produção é de $80 \%$, enquanto aos servidores cabiam, apenas, $20 \%$.

As relações da Chefia sôbre o grupo são indispensáveis, cabendo-lhe estimulá-lo, fazendo-o sentir-se como membro importante do sistema.

O Chefe eficiente deve adotar uma atitude democrática e desprezar o tipo de comportamento adotado pelos Chefes autocratas e aristocratas, sempre que possivel.

Para isso, deverá fazer sentir a seus subordinados que êles têm: direitos e vantagens, direito de defesa, de opinar, assegurados na regulamentação adequada.

Para disciplinar as funções temos as normas, práticas e atividades.

Sôbre funcionários, encontramos normas, práticas e atividades, nos seguintes documentos: Constituição, Estatuto, Leis, Decretos, Regimento, Regulamentos, Portarias, Circulares, Jurisprudência etc.

A observação e o conhecimento de tais documentos darão, ao Chefe e ao servidor, um equilibrio entre direitos e vantagens e deveres e obrigações, pois, fixam os limites que não deverão ser transpostos por qualquer dos dois. 


\subsection{1. - Material}

Relativamente ao material, deve o Chefe conhecer os principios e métodos de que se utilizará para conseguir produtividade e economia.

Preliminarmente, porém, ter informações sôbre como deverá proceder para adquirir o material de que necessitará em seu trabalho.

A compra deve, também, obedecer a certos requisitos dos quais o $10^{\circ}$ é que sejam determinadas as espécies de produtos a serem adquiridos, seguida esta fase pela previsão do volume a comprar e, finalmente, pela fixação do tempo na entrega.

Deve a compra acompanhar as condições e tendências dos mercados, pois, a política da produção vai depender da boa ou má politica que foi observada na compra.

O tipo de material a ser adquirido deve ser bem especificado a fim de melhor orientar o fornecedor e o consumidor e, muitas vêzes, informações valiosas são prestadas ao consumidor no sentido de ajustar melhor o material às suas necessidades, pelo próprio fornecedor, em virtude da observância de tal requisito.

No que tange a prazo e quantidade, deve o Chefe, sempre, pedir em quantidade e prazo razoáveis, para que possam ser atendidos por maior número de fornecedores, possibilitando melhor escolha do produtor e das condições de compra.

Sempre que possivel, deve o Chefe simplificar a chamada burocracia que, geralmente, é a responsável pela desistência de fornecedores e elevaৎ̧ão dos preços.

A nomenclatura do material é, por vêzes, também, fator dificultoso para sua aquisição, devendo por isso, ser o mais simples possivel e tornado público às firmas concorrentes a fim de que as mesmas conheçam o nome técnico que, nem sempre, é o mesmo usado no comércio.

Esses são os cuidados preliminares na compra.

Abordaremos, agora, a compra pròpriamente dita.

Os artigos são grupados em classes cujo fornecimento é feito, sendo mesma classe, pelo mesmo fornecedor.

Assim, há os artigos de papelaria, de couro, ferragens, etc.

Feita a concorrência pública para o material de que necessita o órgão, deve o mesmo estabelecer: qualidade, quantidade, prazo de entrega e formas de pagamento.

Recebidas as propostas devem elas ser julgadas tendo em vista o que foi pedido na concorrência bem como as melhores condições apresentadas.

A firma vencedora fará, então, um contrato no qual serão estabelecidas as obrigações de ambas as partes.

Começará, então, por parte da repartição, um contrôle do prazo a fim de que o fornecedor nấo acarrete prejuizos ao ritmo da produção com o atraso ou falta do cumprimento do que lhe foi exigido. 
Cumprido o contrato pela entrega do material pedido, deve o mesmo ser contado e inspecionado quanto à qualidade, pelos métodos exigidos a cada caso.

Satisfeitas essas exigências, será efetuado o pagamento que encerra a compra.

\subsection{2. - ORÇAMENTO}

É o Orçamento o programa, o plano de trabalho a ser realizado pelo Presidente da República através dos diversos setores da Administração Pública.

É por isso também chamado lei de meios, porque de fato fornece os meios necessários à consecução das atividades gerais e específicas do Estado.

Guardando as devidas proporções, o orçamento de uma pequena unidade de trabalho é o programa de sua ação, para um ano, traduzido em cruzeiros ou recursos.

Deve o Chefe interessar-se junto à alta administração no sentido de que suas verbas sejam majoradas e mantidas, segundo as necessidades do seu serviço.

Tal medida visa a que seu plano de trabalho e expansão não se vejam prejudicados por falta dos elementos de que precisará, pois, por vêzes, se torna necessário certo tipo de material e despesas com pessoal específicas de determinado serviço e imprevistas na verba geral das mesmas. Se fôssem resolvidos pela verba geral, nem sempre poderiam ser realizados.

Entretanto, há, também, desperdícios no uso do numerário, quando, feitos os gastos necessários «torram -se» os cruzeiros restantes a fim de que não haja cortes no Orçamento vindouro.

É errado êsse critério como o é, também, o de cortar pelo fato de haver saldo, sem consultar o órgão interessado sôbre as reais necessidades daquele.

Relativamente ao Orçamento, cabe ao Chefe fixar seus objetivos tendo em vista os meios orçamentários disponiveis e o prazo para sua realização e, sobretudo, zelar para que os dinheiros públicos ou privados, no caso da emprêsa particular, sejam funcional e honestamente utilizados.

\section{FATÔRES E CONDIÇÕES DETERMINANTES DO AUMENTO OU BAIXA DA PRODUÇÃO}

\section{$7.0-\mathrm{O}$ meio}

Os estudiosos sôbre os fatôres que, de alguma forma, atuam na produção, aumentando ou baixando seu índice, concluíram que:

- o meio é fator importante na produção, desde a iluminação até as instalações adequadas ou não, da emprêsa. 


\section{1 - O salário}

Pode aumentar, consideràvelmente, a produção.

Coube a EMERSon criar um sistema de remuneração pelo qual os acréscimos de salários decorriam das proporções do aumento do rendimento.

GANTT estabeleceu prêmios àqueles que realizassem as tarefas fixadas.

Mas, sobretudo, no adequado das

\section{2. - Técnicas de pessoal}

é que encontraremos a solução do problema da baixa na produção, pelo uso de formas capazes de alcançar o rendimento máximo e o êxito completo da emprêsa.

\section{CONCLUSÕES}

A vista do exposto e face a outras inferências, podemos concluir:

a) A grande e principal função da Chefia é produção, é rendimento máximo, é produtividade ótima de sua unidade de trabalho.

b) Para lograr a contento sua finalidade, a Chefia, necessàriamente, que dispor de pessoal, material, recursos financeiros, afora instrumental, organização e métodos de trabalho, além de equipamentos e instalações adequados.

c) De todos os fatôres da produção, a Chefia verifica que o mais expressivo, o dinamizante dos demais, é, sem dúvida, o homem, o potencial humano disponivel.

d) Todos os elementos da produção merecem cuidados especiais, mas, reconhecidamente, o homem é o que mais atenção tem que receber da Chefia.

e) Para aumentar a produtividade, além do emprêgo racional dos demais fatôres, deverá a Chefia participar ativamente da Administração do Pessoal da emprêsa, influindo no recrutamento, na seleção, no estágio probatório, nas promoções, nas transferências e comissões, no bem-estar do empregado, na política de salários e estimulos e, sobretudo, na realização de estudados programas de treinamento que visem a mais e mais eficiência de cada servidor.

f) Uma das atribuições da Chefia é, reconhece-se hoje, a de treinar sua equipe, com o objetivo precípuo de conseguir que cada empregado faça mais, melhor, em menos tempo, com menor gasto e a inteiro contentamento de tôdas as partes interessadas - numa palavra - produção crescente.

g) Lançando mão dos modernos conhecimentos de relações humanas no trabalho, a Chefia poderá, como nunca, sistemàticamente, lograr aumento da produção de seu grupo de trabalho.

h) Reconhecendo a Chefia que salário é importante para o empregado, mas consideração é, também, tão ou mais importante para o moral do servidor, continuas elevações de nivel de produção têm sido conseguidas. 
i) Dando exemplo de que aplica e fazendo sua turma aplicar os principios de imparcialidade, neutralidade, etc. a Chefia poderá promover satisfação permanente de todos e aumentar a produção para mais desejáveis padrões.

j) Esforçando-se a Chefia, diuturnamente, em ser democrática, positiva, inspiradora, sobretudo, lider e não capataz, com isso conseguindo colaboração total do grupo. recordes de produção (ou seja produtividade) são logrados. 